\title{
Prevalence of Bovine Tuberculosis in and Around Nekemte Town Western Oromia, Ethiopia
}

\author{
Gutu Kitila ${ }^{1}$ and Bedaso Kebede ${ }^{2 *}$ \\ ${ }^{1}$ Ethiopian Public Health Institute, Addis Ababa, Ethiopia \\ ${ }^{2}$ Veterinary Drug and Animal Feed Administration and Control Authority, Addis Ababa, Ethiopia
}

Received: 12 October, 2017; Accepted: 14 November, 2017; Published: 03 Janaury, 2018

*Corresponding author: Bedaso Kebede, Veterinary Drug and Animal Feed Administration and Control Authority, Addis Ababa, Ethiopia. E-mail: kebede.bedaso@yahoo.com

\begin{abstract}
The study conducted from January to June, 2014 with aim of determining prevalence of bovine tuberculosis and its associated risk factors in and around Nekemte town of western Oromia, Ethiopia. Bovine tuberculosis is a globally distributed chronic disease of animals and humans can be affected by the consumption of raw milk which is a serious public health concern. This study revealed that herd $(26.6 \%)$ and individual $(13.7 \%)$ prevalence of tuberculosis in study area among 128 herd sizes and 394 individual dairy cattle tested using Comparative Intradermal Tuberculin Test (CIDT). Herd prevalence of bovine tuberculosis insignificantly associated $(\mathrm{P}>0.05)$ with herd size and animals greater or equal to six were 2.3 times more likely to be infected (odds ratio $\mathrm{OD}=2.32,(95 \% \mathrm{CI}=1.01,5.33)$ with bovine tuberculosis. Individual prevalence of bovine tuberculosis was significantly associated $(\mathrm{P}<0.05)$ with the different age categories of animals but insignificantly associated $(P>0.05)$ the other variables and female cattle affected about four times than male. Therefore, routine control measures should be undertaken regularly.
\end{abstract}

Keywords: Bovine tuberculosis; Dairy cattle; Prevalence; Herd size; Comparative Intradermal Tuberculin test; Nekemte

\section{Introduction}

Bovine tuberculosis is a disease that characterized by progressive development granulomatous in tissues and organs of vertebrate animals and humans that caused by Mycobacterium bovis $[2,12,21]$. It is extensively distributed throughout the world which cause impact on income gain from animal production and result in zoonotic importance in humans [28]. Hence, Bovine tuberculosis potentially threatens African cattle and humans as closely $85 \%$ and $82 \%$ respectively [7]. Human tuberculosis that estimated 10 to $15 \%$ are caused by Mycobacterium bovis which is still common in developing countries because of pasteurization of milk is not routinely carried out [8].

In Tropics countries to increase demand for milk and milk products introduction of high-grade dairy cows is a quick and suitable option when compared to dairying indigenous cattle solely $[13,27]$. For this reason, Channel Island breeds and Friesians were imported in the countries after Second World War. Increments of milk yield were not enough by introduction of high grade dairy cows. So, improved feeding and intensive management conditions are mandatory [1]. However, Tuberculosis becomes a serious problem in cattle after European breeds used for the intensive dairy industry $[11,18,24]$. In Ethiopia situation bovine tuberculosis is the most prevalent disease of cattle and humans. Many reports indicated that prevalence of bovine tuberculosis ranges from $0.8 \%$ to $50 \%$ minimum value in extensive farming and maximum value in intensive farming [14,26,29]. Even though, there is a paucity of epidemiological information on bovine tuberculosis in and around Nekemte town. Therefore, the objective of this study is to determine prevalence of bovine tuberculosis and its associated risk factors in and around Nekemte town western Ethiopia.

\section{Methods and Materials}

\section{Study area}

The study was undertaken from January to June, 2014 in and around Nekemte town of dairy farms which is geographically located at latitude and longitude of $905^{\prime} \mathrm{N} 36033^{\prime} \mathrm{E}$, an elevation of 2,088 meters above sea level and $335 \mathrm{~km}$ westward far from capital city Addis Ababa (Figure 1).

\section{Study animals and Sampling}

The study was conducted on all breeds of cattle kept for purpose dairy which varies in age, sex, breed, body condition and management. Convenient sampling method was employed to the study area and all the animals in the farms were tested. A total of 394 dairy cattle and 128 herd sizes were tested by Comparative Intradermal Tuberculin Test.

\section{Comparative Intradermal Tuberculin Test}

The Cattle skin was shaved at two sites (12 cm apart) on the right-hand side of the mid-neck area in adult cattle but in young cattle both side of the neck was shaved for injection with PPD. The skin thickness was measured with calipers before the tuberculin was injected. Aliquots of $0.1 \mathrm{ml}$ of 2,500 international units (IU) per milliliter (ml) of bovine Purified Protein Derivative (PPD) (Veterinary Laboratories Agency, Addle stone, United Kingdom), and $0.1 \mathrm{ml}$ of 2,500 IU/ml of avian PPD (Veterinary Laboratories Agency, Addle stone) were injected into the dermis at these sites. After 72 hours, the thickness of the skin at the injection sites 


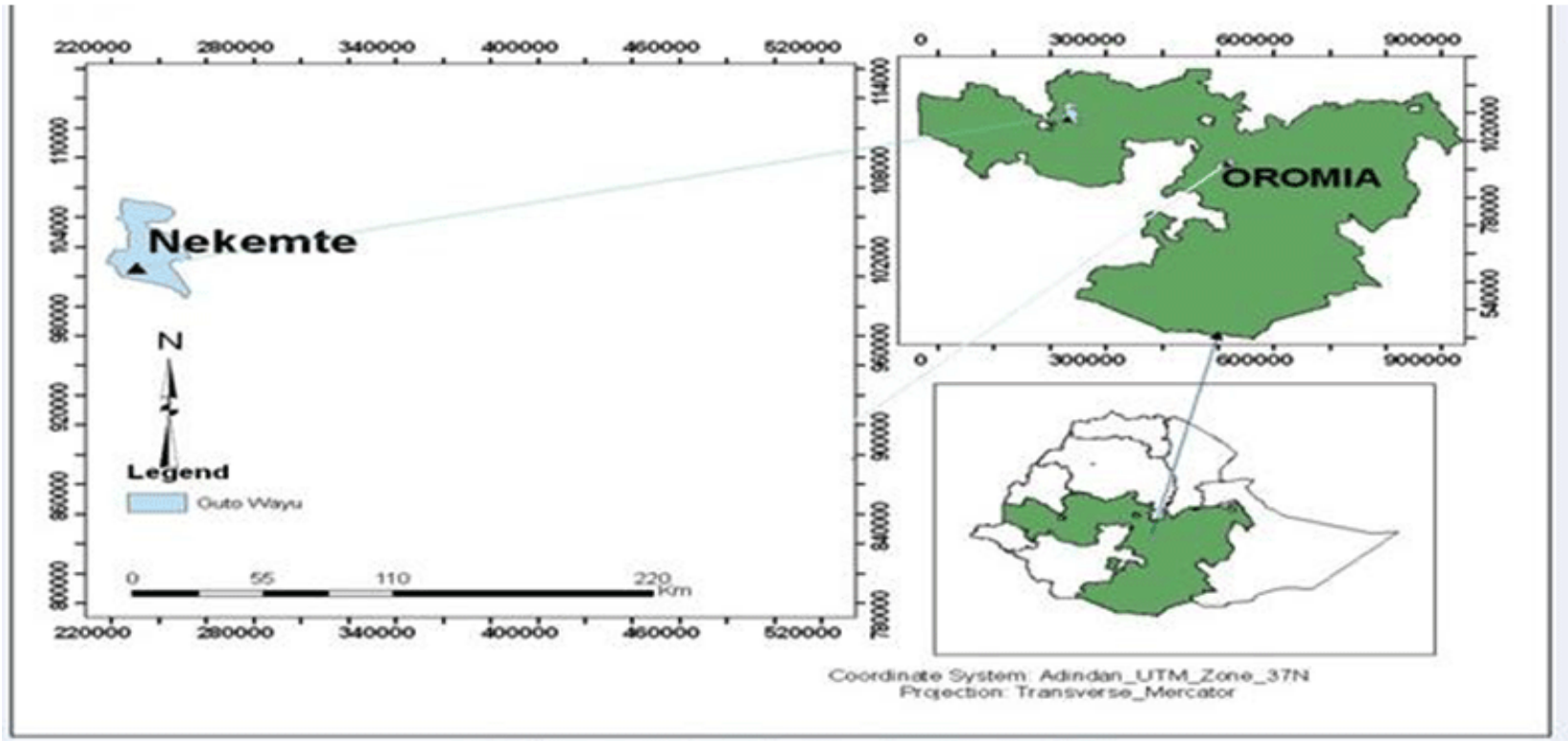

Figure 1: Source (NMSA, 2013)

was measured, using calipers. The results were interpreted in accordance with the recommendations of the World Organization for Animal Health (OIE) $[19,20,21]$. Shortly, when the change in skin thickness was greater at the avian PPD injection site, the animal was considered positive for mycobacterium species other than the mammalian type (M. tuberculosis and M. bovis). However, when an increase in thickness was observed at both sites, the difference in thickness was considered. Thus, if the increase in thickness at the injection site for bovine PPD (B) was greater than that at the avian PPD site (A), and if B minus A was less than $2 \mathrm{~mm}$, the animal was classified as negative for bovine TB. If $B$ minus A was between $2 \mathrm{~mm}$ and $4 \mathrm{~mm}$, or above $4 \mathrm{~mm}$, the animal was classified as either suspect, or positive, respectively.

\section{Data analysis}

The collected data was entered into Microsoft Excel spread sheet and analyzed by using SPSS version 20. Relationships between test result and potential predictor variables were assessed using chi-square and multivariate logistic regression model. P-values of less than 0.05 were considered statistically significant.

\section{Results}

\section{Herd Prevalence}

The overall herd prevalence of dairy cattle $26.6 \%$ was recorded in and around Nekemte town using comparative intra dermal tuberculin test. Prevalence of bovine tuberculosis insignificantly associated $(\mathrm{P}>0.05)$ with herd size. Animals greater or equal to six were 2.3 times more likely to be infected (odds ratio $\mathrm{OD}=2.32$, $(95 \% \mathrm{CI}=1.01,5.33)$ with bovine tuberculosis (Table 1$)$.

\section{Characteristics at the animal level}

Prevalence of bovine tuberculosis at individual animal was $13.7 \%$ by Comparative Intradermal Tuberculin test. Prevalence of bovine tuberculosis was significantly associated $(\mathrm{P}<0.05)$ with the different age categories of animals but the rest variables were insignificantly associated $(\mathrm{P}>0.05$ ) (Table 2$)$.

Table 1: Effect of herd size on the prevalence bovine tuberculosis

\begin{tabular}{|c|c|c|c|c|c|}
\hline Herd size & Number of herds tested & Number (\%) of herds tested positive & $\mathrm{X}^{2}$-value & P-value & Odds ratio ( $95 \%$ Confidence Interval) \\
\hline$\leq 2$ Animals & 10 & $2(5.9 \%)$ & $4.276 \mathrm{a}$ & 0.118 & 1 \\
\hline 3-5 Animals & 62 & $12(35.3 \%)$ & & & $2.22(0.43-11.49)$ \\
\hline$\geq 6$ Animals & 56 & $20(58.8 \%)$ & & & $2.32(1.01-5.33)$ \\
\hline Total & 128 & $34(26.6 \%)$ & & & \\
\hline
\end{tabular}


Table 2: Associated risk factors effects on prevalence of bovine Tuberculosis of small scale dairy cattle in and around Nekemte town.

\begin{tabular}{|c|c|c|c|c|c|c|}
\hline Variables & Categories & Number of animals & Prevalence & $\begin{array}{l}\text { Adjusted odds ratio } \\
\text { (95\% Confidence } \\
\text { Interval) }\end{array}$ & $\mathrm{X} 2$ & P-value \\
\hline \multirow[t]{3}{*}{ Sex } & Male & 92 & $10(2.5 \%)$ & 1 & & \\
\hline & Female & 302 & $44(11.2 \%)$ & $0.83(0.37-1.87)$ & $0.816 \mathrm{a}$ & 0.366 \\
\hline & Total & 394 & $54(13.7 \%)$ & & & \\
\hline \multirow[t]{5}{*}{ Age } & $\leq 1$ & 76 & $0(0 \%)$ & 1 & & \\
\hline & 3-Jan & 142 & $24(6.1 \%)$ & Very large (0-very large) & & \\
\hline & 6-Mar & 134 & $24(6.1 \%)$ & $1.19(0.43-3.29)$ & $15.312 \mathrm{a}$ & 0.002 \\
\hline & $>6$ & 42 & $6(1.5 \%)$ & $1.11(0.41-2.98)$ & & \\
\hline & Total & 394 & $54(13.7 \%)$ & & & \\
\hline \multirow[t]{4}{*}{ BCS } & Good & 84 & $14(3.6 \%)$ & 1 & & \\
\hline & Medium & 244 & $32(8.1 \%)$ & $1.14(0.43-3.02)$ & $0.835 a$ & 0.659 \\
\hline & Poor & 66 & $8(2.0 \%)$ & $1.03(0.44-2.44)$ & & \\
\hline & Total & 394 & $54(13.7 \%)$ & & & \\
\hline \multirow[t]{3}{*}{ Breed } & Local(Zebu) & 18 & $0(0 \%)$ & 1 & & \\
\hline & Cross & 376 & $54(13.7 \%)$ & Very large (0-very large) & $2.996 a$ & 0.083 \\
\hline & Total & 394 & $54(13.7 \%)$ & & & \\
\hline
\end{tabular}

\section{Discussion}

The current study in and around Nekemte town revealed that the herd prevalence of bovine tuberculosis was $26.6 \%$. This finding is almost two times lower than herd prevalence of tuberculosis (42.6\%) in Wuchale-Jida district [3]. This could be due to herd size of dairy farms when herd size increased it predispose to higher tuberculosis infection. However, herd prevalence of tuberculosis of this study was higher than studies undertaken in Adama (15\%), Bishoftu (5.5\%) and Mekelle (20\%) respectively $[4,25,31]$.

Prevalence of bovine tuberculosis at animal level in the recent finding was $13.7 \%$. In agreement with the previous studies in Wolaita soddo (14.2\%) and Asmara (14.5\%) studied by Ameni et al., 2001 and Omer et al., 2001 respectively [6,22]. However, higher in prevalence than studies conducted in Adama (11\%) and Hawassa (11.6\%) [4,26]. On other hand, the current prevalence of individual animal was lower than studies undertaken in Addis Ababa city $34.1 \%$ and $23.7 \%$ by [23]. Hence, studies on bovine tuberculosis in Addis Ababa city conducted on Holstein breeds, intensive production system and large herd sizes which favor transmission of bovine tuberculosis in the herd $[4,5,9]$.

Regarding to sex of dairy cattle in present study female cattle affected about four times than male by bovine tuberculosis which is in line with the previous finding of Inangolet et al. 2008 [16]. Such susceptibility raised from the management and purpose of dairy cattle like cows confined in bran and kept for long period for production which creates stress on animals and these enhance transmission of bovine tuberculosis among dairy cows [10].

In present study local breeds non-infected when cross breeds infected with the prevalence of $13.7 \%$. This study agrees with previous findings $[14,17,26]$. This could be genetically improved dairy cattle more prone to diseases due to easily suffer poor management and malnutrition. Similar to Zeru et al. 2014 report recent finding pointed medium body condition score dairy cattle suffer more infection than good body condition score [31]. Infectivity of infection increases as deficiency of nutrition values such as proteins, minerals and vitamins raises in the diet [15]

\section{Conclusion and Recommendation}

In Ethiopia bovine tuberculosis still constitutes a public health hazard. Hence, the current study in and around Nekemte town indicates that higher prevalence of tuberculosis in both herd and individual levels. Risk factors female, cross breeds and medium body condition score harbor more infection of tuberculosis in this study. This occurs with small herd sizes which is alarming sign of tuberculosis that herd size is the predisposing factor of bovine tuberculosis. Therefore, routine awareness creation and control measures should be undertaken in the study area.

\section{References}

1. Abaye T, Alemu GW, Beruk Y, Philip C, Gebre-Meskel T. Status of dairying in Ethiopia and strategies for future development. In Proc. 3rd National Livestock Improvement Conference Institute of Agricultural Research, Addis Ababa, Ethiopia. 1991.

2. Amanfu W. The situation of tuberculosis and tuberculosis control in animals of economic interest. Tuberculosis. 2006;86(3-4):330-335.

3. Ameni G, Amenu K, Tibbo M. Bovine tuberculosis prevalence and risk factor assessment in cattle and cattle owners in Wuchale-Jida district, central Ethiopia. Int.J.appl.Res.vet.Med. 2003;1(1):17-26.

4. Ameni G, Erkihun A. Bovine tuberculosis on small-scale dairy farms in Adama Town, central Ethiopia and farmer awareness of the disease. Rev.Sci.Ethiop.Tech. 2007;26(3):711-719. 
5. Ameni G, Hewinson G, Aseffa A, Young D, Vordermier M. Appraisal of interpretation criteria for the comperative intradermal tuberculin test for diagnosis of tuberculosis in cattle in central Ethiopia. Clinical vaccine and Immunology. 2008;15(8):1272-1276.

6. Gobena Ameni, Addis Abeba. Survey on bovine tuberculosis in cattle and its public health implications in cattle-raising families in Wolaita Soddo,southern Ethiopia. Ethiopian J. anim. Prod. 2001;1(1):55-62.

7. Anonymous. Zoonotic tuberculosis (mycobacterium infection): amemorandum from WHO (with participation of FAO). Bulletin of World Health Organization. 1994;72(6):851-857.

8. Ashford DA, Whitney E, Raghynathan P, Cosivi O. Epidemiology of selected mycobacteria that infect humans and other animals. Review of science and Technology, office International des Epizootics. 2001;20(1):325-337.

9. Asseged B, Lübke-Becker A, Lemma E, Taddele K, Britton S. Bovine tuberculosis: a cross-sectional and epidemiological study in and around Addis Ababa. Bull. Anim. Health Prod. Afr. 2000;48(2):71-80.

10. Barlow ND, Kean JM, Hickling G, Livingstone PG, Robson AB. A simulation model for the spread of bovine tuberculosis within New Zealand cattle herds. Prev. Vet. Med. 1997;32(1-2):57-75.

11. Barwineck F, Taylor NM. Assessment of the socio-economic importance of tuberculosis in Turkey and possible strategies for control and eradication. Turkish-German Animal health Information Project, Ankara. 1996;3-45.

12. Buncic S. Integrated Food safety and Veterinary Public Health. 1st ed. CABI, London, UK. 2006;61.

13. Deleeuw PN, Omore A, Staal S, Thorpe W. Small holder dairying in the tropics. Institute of Land and Food research, Melbourne, Australia. 1999.

14. Firdessa R, Tschopp R, Sombo M, Hailu E, Girume Erenso, Teklu Kiros, et al. High prevalence of Bovine Tuberculosis in dairy cattle in central Ethiopia: Implications for the dairy industry and Public health. 2012. doi:10.1371?journal.pone.0052851.

15. GriffinJ, HahesyT, Lynch K, Salman M, Mc Carthy J, Hurley T. The association of cattle husbandry characteristics, environmental factors and farmer characteristics with the occurrence of chronic bovine tuberculosis in dairy herds in the Republic of Ireland. Prev. Vet. Med.1993;17(3-4):145-160.

16. Inangolet F, Demelash B, Oloya J, Opuda-Asibo J, Skjerve E. A crosssectional study of bovine tuberculosis in the transhumant and agropastoral cattle herds in the border areas of Katakwi and Moroto districts, Uganda. Trop. Anim. Health Prod. 2008;40(7):501-508.

17. Kazwala RR, Kambarage DM, Daborn CJ, Nyange J, Jiwa SF, Sharp JM. Risk factors associated with the occurrence of bovine tuberculosis in cattle in the Southern Highlands of Tanzania. Vet. Res. Commun. 2001;25(8):609-614.
18. Kleeberg HH. Human tuberculosis of bovine origin in relation to public health. Rev. sci.tech.off.int. Epiz. 1984;3(1):11-32.

19. Kiros T. Epidemiology and zoonotic importance of bovine tuberculosis in selected sites of Eastern Shoa, Ethiopia. MSc Thesis. Free University of Berlin and Addis Ababa University. 1998.

20. National Meteorology Services Agency (NMSA). Monthly report on temperature and Rainfall Distribution for Eastern Wollega Zone, Regional Metrological Office, Nekemte, Ethiopia. 2013

21. OIE. Bovine Tuberculosis. In: Manual of diagnostic Tests and Vaccines for Terrestrial animals. World Organization for Animal Health. 2010;683-698.

22. Omer MK, Skjerve E, Woldehiwet Z, Holstad G. A cross-sectional study of bovine tuberculosis in dairy farms in Asmara, Eritrea. Trop. anim. Hlth Prod. 2001;33 (4):295-303.

23. Pandey GS, Hang'ombe BM, Mushabati F and Kataba A. Prevalence of tuberculosis among southern Zambian cattle and isolation of Mycobacterium bovis in raw milk obtained from tuberculin positive cows, Veterinary World. 2013;6(12):986-991.

24. Radostitis OM, Hinchcliff KW, Constable PD, Gay CC. Diseases caused by mycobacterium of cattle, pigs, goats and horses, 10th ed. Saunders WB Co. Elsevier, London, London. 2006:1007-1044.

25. Redi N. Bovine Tuberculosis: Study on prevalence on small holder farms and consciousness of households on its transmission at Asela town, Southern Ethiopia. DVM thesis. Faculty of Veterinary Medicine, Addis Ababa University, Debrezeit, Ethiopia. 2003.

26. Regassa A, Medhin G, Ameni G. Bovine tuberculosis is more prevalent in cattle owned by farmers with active tuberculosis in central Ethiopia. Veterinary Journal. 2008;178(1):119-125.

27. Tegegne A, Gebrewold A. Prospects for peri-urban dairy development in Ethiopia. In: Proc. 5th National Conference of the Ethiopian society of Animal production, Addis Ababa, Ethiopia. 1998.

28. Tenguria KR, Khan FN, Quereshi S, Pandey A. Epidemiological study of Zoonotic Tuberculosis Complex (ZTBC). World Journal of science and Technology. 2011;1(3):31-56.

29. Tschopp R, Schelling E, Hattendorf J, Young D, Aseffa A, Zinsstag J. Repeated cross-sectional skin testing for bovine tuberculosis in cattle kept in a traditional husbandry system in Ethiopia. Veterinary Record. 2010;167(7):250-256. doi:10.11361vr.c3381.

30. World Organisation for Animal Health (OIE). Bovine tuberculosis. In Manual of standards for diagnostic tests and vaccines, 4th Ed. OIE, Paris. 2000:451-463.

31. Zeru F, Romha G, Berhe G, Mamo G, Sisay T, Ameni G. Prevalence of bovine tuberculosis and assessment of cattle owners' awareness on its public health implication in and around Mekelle, Northern Ethiopia. Journal of Veterinary Medicine and Animal Health. 2014;6(6):159-167. doi: 10.5897/JVMAH2014.0288 